\title{
NOTAS SOBRE EL ESTATUTO \\ DE LAS CONFESIONES RELIGIOSAS EN LA LEY ORGÁNICA DEL DERECHO DE ASOCIACIÓN
}

JOSÉ RAMÓN POLO SABAU

1. INTRODUCCIÓN.-2. LA NATURALEZA JURÍDICA DE LAS CONFESIONES RELIGIOSAS EN LA LODA.-3. LA DETERMINACIÓN DEL ÁMBITO DE APLICACIÓN DE LA LODA Y EL RÉGIMEN ESPECIAL DE LAS CONFESIONES RELIGIOSAS. - 4. EL ESTATUTO DE LAS CONFESIONES ANTE LA EXIGENCIA DE DEMOCRACIA INTERNA ASOCIATIVA EN LA LODA.-5. LA MENCIÓN IMPLÍCITA DE LAS ASOCIACIONES CATÓLICAS EN LA LODA Y EL PESO DE LA TRADICIÓN CONCORDATARIA.

\section{INTRODUCCIÓN}

El ordenamiento jurídico español contempla un tipo particular de entidades, las confesiones religiosas, constitutivas de una singular categoría jurídica en la que se hace residir, a su vez, una especial personalidad jurídica civil, la personalidad jurídica religiosa. A estas entidades, detentadoras de la tipicidad religiosa en nuestro Derecho, se alude en distintas normas empleando una variada nomenclatura (confesiones religiosas, comunidades religiosas, entidades religiosas, etc.), que, no obstante, puede ser reconducida al concepto unitario de confesión religiosa que, además de ser el que emplea el constituyente en el artículo 16.3, suele ser generalmente admitido en sede doctrinal como aquel que resulta más apto para designar jurídicamente a este tipo de sujetos colectivos dotados de un régimen específico en nuestro ordenamiento constitucional.

La naturaleza jurídica que corresponde a las confesiones religiosas en nuestro Derecho ha sido tradicionalmente, y aún hoy lo sigue siendo, una cuestión harto discutida entre la doctrina científica, distinguiéndose a este respecto, básicamente, dos grandes planteamientos que son, por lo demás, radicalmente contrapuestos: de un lado, las confesiones religiosas son, para algunos autores, la 
manifestación típica de la llamada vertiente institucional de la libertad religiosa, una dimensión específica que se reputa en principio distinta de las vertientes de ejercicio individual y colectivo de este derecho fundamental y que confiere a las confesiones una naturaleza propiamente institucional en el ordenamiento español (esta posición, a mi juicio tan llamativamente anacrónica y ajena a la vigencia del principio personalista en que se inspira nuestro sistema constitucional de derechos y libertades, se encuentra particularmente extendida entre los cultivadores del Derecho Eclesiástico del Estado); para otros autores, por el contrario, las confesiones religiosas deben más bien ser concebidas jurídicamente como asociaciones, fruto, por tanto, del ejercicio colectivo de un derecho de titularidad en última instancia individual —el derecho de asociación, en este caso en materia religiosa-, distinguiéndose a su vez, dentro de esta segunda línea de pensamiento, en primer lugar aquellos autores que postulan que las confesiones son asociaciones sumamente peculiares y por ello sometidas exclusivamente a su legislación especial, y, en segundo término, aquellos otros que consideran que las confesiones religiosas, sin perjuicio de su propia mención específica en el artículo 16 de la Constitución, no son otra cosa que entidades de base asociativa que se acomodan fielmente a la categoría de las asociaciones de relevancia constitucional y, consecuentemente, se encuentran también plena y directamente al amparo de los requisitos y condiciones mínimos que conforman la garantía común asociativa en el artículo 22 de la ley fundamental.

En mi criterio, la posición que resulta sin duda más atendible, a la luz de una interpretación constitucionalmente adecuada de las disposiciones que integran el régimen especial de las confesiones en nuestro Derecho, es aquella que las identifica con la categoría de las asociaciones de relevancia constitucional y que, por lo tanto, obliga a concebirlas, desde la óptica del ordenamiento español, como una más de las manifestaciones del fenómeno asociativo que se desarrolla, del mismo modo que lo hacen las restantes asociaciones de relevancia constitucional, al abrigo tanto de su legislación especial (en este caso la Ley Orgánica de Libertad Religiosa de 1980 — en adelante, LOLR_-) como de la garantía común asociativa en la Constitución y su desarrollo directo en la LODA (1).

El Tribunal Constitucional se pronunció al fin sobre esta cuestión en su sentencia de 15 de febrero de 2001 (STC 46/2001) relativa a los caracteres que

(1) Vid. más ampliamente J. R. POLO, La naturaleza jurídica de las confesiones religiosas en el Derecho Constitucional español, Málaga, 2008; IDEM, «De nuevo sobre la naturaleza jurídica de las confesiones religiosas y su discutida relación con la garantía común asociativa en el Derecho español», en Revista General de Derecho Canónico y Derecho Eclesiástico del Estado, núm. 21, 2009; IDEM, Estudios sobre la Constitución y la libertad de creencias, Málaga, 2006. 
debe revestir el proceso de inscripción en el Registro de Entidades Religiosas, pero lo hizo de un modo tan confuso y aporético, desatendiendo su propia doctrina sobre el significado de la garantía común asociativa en la Constitución e incurriendo en numerosas imprecisiones y contradicciones internas entre los distintos razonamientos empleados en la fundamentación de su fallo, que difícilmente pueden extraerse de este pronunciamiento conclusiones claras y definitivas a propósito de la naturaleza jurídica de las confesiones en nuestro Derecho, y más bien, como he tenido ocasión de exponer detalladamente en otra sede, cabe extraer de la doctrina sentada en esta resolución argumentos para sostener, a un tiempo, una cosa y su contraria, arrojando, por lo tanto, más sombras que luces sobre la cuestión que ahora nos ocupa y dejando así abiertos algunos interrogantes decisivos que conciernen al corazón mismo del problema jurídico planteado (2).

Así las cosas, la promulgación, en 2002, de la Ley Orgánica del Derecho de Asociación (en adelante, LODA), dictada en desarrollo del derecho fundamental consagrado en el artículo 22 de la Constitución, se produjo en un contexto legislativo y doctrinal en buena medida incierto por lo que a la naturaleza jurídica de las confesiones se refiere. Por ello, cabía legítimamente esperar del legislador de la libertad de asociación la adopción de un criterio sólido e inequívoco acerca de la naturaleza de las confesiones y, en su caso, acerca del tipo de relación existente entre su legislación especial y la garantía común asociativa en la Constitución. Sin embargo, lejos de satisfacer esta razonable expectativa, la LODA se ha pronunciado sobre este tema - y sobre algunos otros - de un modo en algunos aspectos no menos contradictorio de lo que lo hizo el Tribunal Constitucional en la STC 46/2001, incurriendo ostensiblemente en algunas aporías y antinomias que, literalmente, han sembrado el desconcierto entre un amplio sector de la doctrina científica y obligan al intérprete a realizar un notable esfuerzo de integración para tratar de dar un sentido coherente a la nueva regulación en su inserción sistemática en nuestro ordenamiento constitucional.

Pese a todo, dejando ahora de lado por un momento las dudas e interrogantes a que ha dado pie tanto la doctrina del Tribunal Constitucional como la nueva regulación instaurada por la LODA en esta materia, lo cierto es que la naturaleza de las confesiones religiosas en nuestro Derecho puede, en mi opinión, deducirse sin excesiva dificultad de una adecuada interpretación sistemática de su legislación especial a la luz de la doctrina sentada por el propio Tribunal

(2) Vid. J. R. POLO, La naturaleza jurídica de las confesiones religiosas..., op. cit., págs. 171196. 
Constitucional en torno al significado y alcance de la garantía común asociativa en la norma iusfundamental. A este respecto, resulta determinante el sentido de la jurisprudencia constitucional recaída en torno al régimen de las asociaciones de relevancia constitucional y su relación con el contenido del artículo 22 de la Constitución, y si ya lo era antes de la promulgación de la LODA cuando algunos autores postulábamos que las confesiones pertenecían propiamente a esa categoría asociativa, más aún lo es ahora que esta norma ha confirmado esa idea al afirmar expresamente que las confesiones religiosas son asociaciones de relevancia constitucional. De este modo, las incongruencias y contradicciones que cabe detectar en la propia LODA respecto de esa premisa fundamental, particularmente evidentes en algunos casos como se ha encargado de subrayar buena parte de la doctrina científica, deben ser necesariamente sometidas a contraste con los principios constitucionales que presiden este sector normativo, en una tarea de construcción dogmática que ha de buscar en lo posible la integración de la norma legal en un sentido acorde con los preceptos constitucionales y, de no ser ello posible, ha de denunciar el derecho inválido por contradictorio con la Constitución.

Desde estos presupuestos, en las páginas que siguen nos disponemos a examinar el significado de las normas que en la LODA delimitan el estatuto de las confesiones religiosas, poniendo especial énfasis en aquellos aspectos que en principio plantean mayores dificultades de adecuación a los postulados constitucionales y particularmente al contenido de la garantía común asociativa en el artículo 22.

\section{LA NATURALEZA JURÍDICA DE LAS CONFESIONES RELIGIOSAS EN LA LODA}

De un modo que no deja lugar a la duda, en la Exposición de Motivos de la ley se afirma que nuestra Constitución, «partiendo del principio de libertad asociativa, contiene normas relativas a asociaciones de relevancia constitucional como los partidos políticos (art. 6), los sindicatos (arts. 7 y 28), las confesiones religiosas (art. 16), las asociaciones de consumidores y usuarios (art. 51), y las organizaciones profesionales (art. 52), y de una forma general define, en su artículo 22, los principios comunes a todas las asociaciones eliminando el sistema de control preventivo, contenido en la Ley 191/1964, de 24 de diciembre, de Asociaciones, y posibilitando su ejercicio» (la cursiva es mía).

Como consecuencia de esta premisa, el legislador asume y hace suya la doctrina sentada por el Tribunal Constitucional en torno a la relación existente entre la garantía común asociativa en el artículo $22 \mathrm{CE}$, de un lado, y los regí- 
menes especiales propios de cada uno de los tipos de asociación de relevancia constitucional, de otro, adoptando, pues, el criterio de que las garantías que se establecen en cada uno de dichos regímenes especiales se añaden y no sustituyen a las del artículo 22, constituyendo este precepto el fundamento constitucional último de todas las modalidades asociativas, incluyendo, por supuesto, a las asociaciones de relevancia constitucional. Y así, también en la Exposición de Motivos, se advierte que «la necesidad ineludible de abordar el desarrollo del artículo 22 de la Constitución, mediante Ley Orgánica al tratarse del ejercicio de un derecho fundamental (art. 81), implica que el régimen general del derecho de asociación sea compatible con las modalidades específicas reguladas en leyes especiales y en las normas que las desarrollan, para los partidos políticos, los sindicatos, las asociaciones empresariales, las confesiones religiosas, las asociaciones deportivas, y las asociaciones profesionales de Jueces, Magistrados y Fiscales. Con este objetivo se establece un régimen mínimo y común, que es, además, el régimen al que se ajustarán las asociaciones no contempladas en la legislación especial».

El criterio que anticipa aquí el legislador del derecho de asociación es claro: las confesiones religiosas son asociaciones de relevancia constitucional y, como tales, además de su sujeción inmediata al régimen delineado en su legislación específica, se encuentran también plenamente sometidas al amparo de la garantía común asociativa en el artículo 22 de la Constitución, conformador de un régimen común y mínimo al que necesariamente habrá de adecuarse la normativa especial en su interpretación y aplicación efectivas. La garantía constitucional de la libertad de asociación en el artículo 22 constituye, en suma, lo que podríamos considerar como el núcleo básico del régimen constitucional de las confesiones religiosas, haciendo uso de la fórmula que ha empleado a estos efectos el Tribunal Constitucional a propósito del régimen de los partidos políticos que también son asociaciones de relevancia constitucional (cfr. STC 56/1995, FJ 3).

De ahí que, en la propia Exposición de Motivos, se indique que se «establece un régimen mínimo y común, que es, además, el régimen al que se ajustarán las asociaciones no contempladas en la legislación especial» (la cursiva es mía), lo que significa que ese régimen mínimo y común, como su propio nombre indica, es aplicable por definición a todas las modalidades asociativas, gocen o no de una legislación especial. Buena parte de los autores que adoptan el criterio de la desconexión de las confesiones del régimen del artículo 22 de la Constitución se remiten, en apoyo de su tesis, al pasaje de la Exposición de Motivos que se acaba de transcribir, pero a menudo lo hacen obviando por completo la presencia en el mismo del adverbio que he subrayado y que confiere al texto 
en cuestión un significado preciso y plenamente acorde con la jurisprudencia constitucional sobre la garantía común asociativa.

En consonancia con esta idea de la plena aplicabilidad a las confesiones del contenido del artículo 22, a mi juicio fruto de una correcta interpretación de las disposiciones aquí implicadas y constitucionalmente sin duda adecuada, la Disposición Final Segunda de la LODA proclama el carácter supletorio de la ley respecto de cualesquiera otras que regulen tipos específicos de asociaciones «excepto en aquellos preceptos que tienen rango de Ley Orgánica», es decir, excepto en aquellos preceptos que constituyen el desarrollo directo del derecho fundamental de asociación consagrado en el artículo $22 \mathrm{CE}$ y que, por ello mismo, resultan de aplicación directa e inmediata, que no meramente supletoria, a todas las modalidades del fenómeno asociativo, también a las asociaciones dotadas de un estatuto propio ya en el mismo texto iusfundamental como es el caso de las confesiones religiosas (excepción hecha únicamente, como se sabe, de las asociaciones privadas de configuración legal constituidas para el ejercicio de funciones administrativas, que, sin dejar de ser asociaciones, no se constituyen, sin embargo, al amparo del art. 22 de la Constitución).

Además, a diferencia de lo establecido en la Exposición de Motivos, a la que pudiera acaso concederse sólo un valor jurídico indirecto como criterio hermenéutico que concurre al proceso de interpretación y aplicación de los preceptos legales propiamente normativos, lo estipulado en la mencionada cláusula de supletoriedad forma parte del contenido estrictamente normativo de la ley, $\mathrm{y}$, como tal, viene a confirmar en el orden prescriptivo la naturaleza asociativa de las confesiones y la plena aplicabilidad a este ámbito objetivo de lo previsto en el artículo 22 de la Constitución. Quienes, en el ámbito doctrinal, propugnan la falta de vinculación entre el estatuto de las confesiones y el régimen común del artículo 22 de la Constitución acuden a menudo, en supuesta defensa de sus tesis, al contenido de la mencionada cláusula de supletoriedad de la que suelen extraer la idea de que la LODA sólo resulta de aplicación supletoria a las confesiones religiosas puesto que disponen de una legislación especial, pero resulta llamativo que con frecuencia lo hagan omitiendo por completo cualquier referencia al primer inciso de dicha cláusula que, como se ha podido comprobar, de manera inequívoca desmiente esa proclamada desvinculación y por el contrario se acomoda fielmente al significado constitucional del artículo 22 y su plena aplicabilidad, directa e inmediata, a todas las asociaciones, también a las dotadas de una legislación especial.

Así pues, a la luz de lo que se acaba de exponer, el legislador del derecho de asociación habría respaldado con su nueva regulación la tesis que vengo 
defendiendo desde hace tiempo sobre este asunto (3), aunque no así la que me atribuyen algunos autores que han caracterizado erróneamente mi propia posición al respecto, al señalar, en esencia, que lo que yo sostengo sobre este tema es que las confesiones religiosas están sometidas al artículo 22 de la constitución, y no al artículo 16 (4), como si proclamar la plena aplicabilidad a las confesiones de la garantía constitucional asociativa implicase, necesariamente, dejar de lado su propia regulación específica en la ley de libertad religiosa y reclamar su reconducción inevitable al régimen general asociativo y su inscripción más bien en el Registro General de Asociaciones, en detrimento de su estatuto propio concerniente al Registro de Entidades Religiosas. Pero lo cierto es que no es esto en absoluto lo que he venido postulando sino, muy al contrario, la necesidad de interpretar y aplicar ese estatuto especial en la ley de libertad religiosa de conformidad con lo establecido en la garantía común asociativa y en su desarrollo orgánico en la LODA, habida cuenta de que esa garantía común del artículo 22 de la Constitución es directa e inmediatamente aplicable a todas las modalidades asociativas sin excepción (o con la única excepción antes apuntada de las asociaciones privadas de configuración legal), y esta concepción de base es, precisamente, la que se ha visto refrendada en la nueva ley del derecho de asociación, a tenor de lo que se desprende tanto de su Exposición de Motivos como del contenido de su cláusula de supletoriedad.

Y en tal sentido, además, puede y debe ser entendido el reconocimiento, en el artículo 2.1 de la LOLR, del derecho de toda persona a asociarse para desarrollar comunitariamente sus actividades religiosas «de conformidad con el ordenamiento jurídico general y lo establecido en la presente Ley Orgánica», pues, en efecto, el régimen de acceso al Registro de Entidades Religiosas instaurado en esta ley y en sus disposiciones de desarrollo debe hacerse compatible con los requisitos mínimos que en el ordenamiento jurídico general se establecen para el ejercicio del derecho de asociación en el artículo 22 del texto fundamental, lo que implica, por ejemplo, que la inscripción en ese registro especial lo será a los solos efectos de publicidad y nunca a los efectos de control sobre los fines de la entidad.

(3) Una tesis que, justo es reconocerlo, es en gran medida directamente tributaria del planteamiento que, a su vez, viene sosteniendo sobre este tema J. A. SOUTO en los últimos años: vid, por ejemplo, Comunidad política y libertad de creencias. Introducción a las Libertades Públicas en el Derecho Comparado, Madrid, 1999.

(4) Vid. al respecto J. R. POLO, La naturaleza jurídica de las confesiones religiosas..., op. cit., págs. 95-101; IDEM, «De nuevo sobre la naturaleza jurídica de las confesiones religiosas...», loc. cit., págs. 14-16. 
Da la sensación, en definitiva, de que, singularmente en el ámbito de la literatura eclesiasticista, no se ha llegado todavía a un entendimiento generalizado del verdadero significado y alcance de la garantía común asociativa en la Constitución y de su relación con los regímenes asociativos especiales, asumido por la jurisprudencia constitucional y comúnmente aceptado en sus caracteres esenciales en el contexto de la dogmática constitucionalista, y seguramente por ello se detectan en aquel ámbito ciertas concepciones, tan extendidas como en mi opinión constitucionalmente infundadas, tales como la idea que propugna que las confesiones religiosas no se encuentran bajo el manto tutelar del artículo 22 puesto que cuentan ya con su propio estatuto iusfundamental en el artículo 16, una idea expresamente desmentida por la jurisprudencia constitucional recaída en torno al régimen de las restantes asociaciones especiales que también cuentan con un estatuto propio en la lex normarum.

\section{LA DETERMINACIÓN DEL ÁMBITO DE APLICACIÓN DE LA LODA Y EL RÉGIMEN ESPECIAL DE LAS CONFESIONES RELIGIOSAS}

Como se ha visto, en relación con la condición netamente asociativa que es atribuible a las confesiones religiosas, existe una perfecta sintonía entre lo anticipado en la Exposición de Motivos de la LODA, de un lado, y lo establecido en la cláusula de supletoriedad de la Disposición Final Segunda de esta ley, de otro. Asimismo, ambos aspectos se encuentran en armonía con la doctrina del Tribunal Constitucional recaída en torno al significado de la garantía común asociativa en la Constitución y su relación con los regímenes asociativos especiales, incluyendo aquellos que están dotados de un estatuto propio ya en el texto fundamental (partidos políticos, sindicatos, confesiones religiosas, etc.).

Sin embargo, el legislador del derecho de asociación, al delimitar el ámbito de aplicación de la LODA, se pronuncia, inopinadamente, en los siguientes términos: «el derecho de asociación se regirá con carácter general por lo dispuesto en la presente Ley Orgánica, dentro de cuyo ámbito de aplicación se incluyen todas las asociaciones que no tengan fin de lucro y que no estén sometidas a un régimen asociativo específico» (art. 1.2); «se regirán por su legislación específica los partidos políticos; los sindicatos y las organizaciones empresariales; las iglesias, confesiones y comunidades religiosas; las federaciones deportivas; las asociaciones de consumidores y usuarios; así como cualesquiera otras reguladas por leyes especiales» (art. 1.3).

Esta singular delimitación del ámbito de aplicación de la ley ha sembrado el desconcierto entre buena parte de la doctrina científica, pues resulta tan osten- 
siblemente antinómica que no parece poder conciliarse en modo alguno con el contenido de la Exposición de Motivos ni con el de la cláusula de supletoriedad de la ley, de una parte, ni tampoco con el sentido de la doctrina del Tribunal Constitucional sobre el contenido del artículo 22 de la Constitución, de otra.

Parece a todas luces evidente que no pueden quedar exceptuadas del ámbito de aplicación de la LODA aquellas asociaciones que estén además sometidas a un régimen específico, sin poner con ello en cuestión la propia naturaleza de esta ley como la norma que opera el desarrollo directo del derecho fundamental consagrado en el artículo 22, como la norma, en suma, que desarrolla orgánicamente los requisitos y condiciones mínimos que integran el estatuto constitucional básico de la libertad de asociación. Esta evidencia, en efecto, ha sido destacada por numerosos autores que, ante la imposibilidad material de encontrar un significado al artículo 1 de la LODA que no resulte tan clamorosamente antinómico, han optado por limitarse a denunciar lo que se considera, simple y llanamente, como una manifiesta equivocación del legislador resultante en una disposición técnicamente defectuosa e imposible de aplicar en sus propios términos sin contravenir con ello el carácter de esta ley como norma de desarrollo del derecho de asociación, sugiriendo la necesidad de interpretar el precepto en un sentido radicalmente distinto al que se desprende de su dicción literal y más acorde con el estatuto constitucional de la libertad de asociación, y llegando incluso, en algún caso, directamente a tener por no puesto al mencionado artículo 1 en sus apartados segundo y tercero (5).

En mi opinión, dada la particular fisonomía del precepto, resulta más que comprensible la perplejidad que han manifestado numerosos autores ante la norma que delimita el ámbito de aplicación de la LODA, pues, más que tratarse de una disposición sólo de difícil justificación a la luz de la pretensión legal de desarrollar íntegramente el derecho de asociación, como se ha dicho (6), estamos aquí en presencia de una norma que, bajo ese mismo prisma, resulta más bien de justificación imposible. Porque, en efecto, a mi modo de ver, su tenor literal contradice, prima facie, la naturaleza a la que la propia ley dice responder en tanto que norma de desarrollo del derecho de asociación (cfr. art. 1.1), y, al

(5) En este sentido, entre otros, J. GONZÁLEZ PÉREZ y G. FERNÁNDEZ FARRERES, Derecho de Asociación. Comentarios a la Ley Orgánica 1/2002, de 22 de marzo, Madrid, 2002, págs. 4243 y 46; L. M. DíEZ-PICAZO, Sistema de derechos fundamentales, Madrid, 2005, pág. 357; A. J. Gómez Montoro, Asociación, Constitución, Ley. Sobre el contenido constitucional del derecho de asociación, Madrid, 2004, pág. 32; J. D. PELAYO, Las comunidades ideológicas y religiosas, la personalidad jurídica y la actividad registral, Madrid, 2007, págs. 76-77.

(6) Cfr. A. MARTín HuerTAS, El contenido esencial del Derecho de asociación, Madrid, 2009, pág. 127. 
mismo tiempo, se opone de manera aparentemente irreductible a lo dispuesto en la Disposición Final Segunda así como a lo anticipado en la Exposición de Motivos de la ley. Ante esta situación, a la doctrina científica le corresponde el papel de tratar de hallar un entendimiento del artículo 1 de la LODA que se acomode a las pautas que determinan la interpretación constitucionalmente adecuada del régimen de la libertad de asociación; dicho de otro modo, a la doctrina científica, como a cualquier otro operador jurídico, le compete llevar a cabo una interpretación integradora del precepto en cuestión a la luz del contenido de la garantía común asociativa en la Constitución.

Aparentemente, la presunción de validez de las normas y el principio de su conservación en el ordenamiento jurídico apuntan hacia la necesidad de agotar la búsqueda de un sentido constitucionalmente adecuado del precepto antes de proclamar su invalidez, y de ello hemos tenido una muestra evidente en el supuesto del artículo 2.5 de la LODA al que, como después veremos, el Tribunal Constitucional ha terminado por conceder un sentido manifiestamente alejado de su dicción literal, si es que no totalmente distinto al que de ésta se desprende, con el propósito declarado de hacer compatible el tenor de ese precepto con uno de los aspectos que integran el contenido esencial de la libertad de asociación en la Constitución. Aun así, en buena técnica jurídica, si en sede doctrinal se estimase que ello no es posible y que el contenido del artículo 1 de la LODA resulta por completo incompatible con los preceptos constitucionales que son aquí de aplicación, lo que en rigor procedería no es otra cosa que la denuncia de la inconstitucionalidad de ese precepto legal. Ello es así sin perjuicio de que, en el plano de la dinámica operativa de la ley en su aplicación efectiva, resulte comprensible que algunos autores postulen directamente la necesidad de tener por no puesto al artículo 1 de la LODA o la conveniencia de interpretarlo en un sentido abiertamente contrario al que se desprende de su tenor literal, pues, de otro modo, en la práctica la ley en este aspecto se convierte en inaplicable por intrínsecamente contradictoria, pero lo cierto es que esa solución no está en rigor contemplada en nuestro Derecho como una forma legítima de afrontar jurídicamente las antinomias que pudieran detectarse en el seno del ordenamiento, para las que se establecen otros mecanismos de depuración como los antes mencionados incluyendo, como último recurso, la denuncia de la inconstitucionalidad del precepto si se demostrase por completo refractario a su integración ordinamental por los cauces hermenéuticos ordinarios.

En consecuencia y por lo que concierne concretamente al estatuto de las confesiones religiosas en la LODA, resultan, de entrada, justificadas las dudas e interrogantes que en la interpretación de la norma pueda suscitar la defectuosa redacción de la cláusula en la que se determina el ámbito de aplicación de la 
ley y, de hecho, se perciben ya algunas muestras muy significativas del confuso contexto en el que se ve obligada a desenvolverse la doctrina científica que se ha ocupado de este asunto a la luz de lo dispuesto en dicha cláusula, quedando en franca evidencia las serias contradicciones a que da pie el texto legal y la enorme dificultad, si es que no acaso directamente la imposibilidad de pronunciarse sobre el estatuto de las confesiones en la LODA en un sentido que no encuentre, a su vez, argumentos en la propia LODA para ser jurídicamente refutado (7). Sin perjuicio de que, en cualquier caso, la naturaleza asociativa de las confesiones y su sometimiento pleno al artículo 22 de la Constitución se pueden ver confirmados tanto en la Exposición de Motivos de la ley como en el sentido inequívoco de su cláusula de supletoriedad, estando ambas además en plena sintonía con el régimen constitucional de la garantía común asociativa, es indudable que la deficiente conformación legal que venimos describiendo permite, cuando menos, explicar la presencia en esta materia de construcciones doctrinales muy distintas que a menudo llegan a conclusiones abiertamente encontradas; a buen seguro, es el propio legislador, como también lo fuera en su día el Tribunal Constitucional merced a su confusa sentencia de 15 de febrero de 2001, el que tiene gran parte de culpa en esta situación, al margen ya del mayor o menor acierto de cada cual en la concreta fundamentación de sus planteamientos científicos.

Lo que, sin embargo, a mi juicio, ya no resulta tan justificado es que, desde algunas posiciones doctrinales, particularmente visibles en el ámbito del Derecho Eclesiástico del Estado, se ignoren por completo las evidentes contradicciones normativas que se aprecian internamente en el contenido de la LODA y las que a su vez se perciben entre el artículo 1 de esa ley y la jurisprudencia constitucional sobre la garantía común asociativa, y se opte simplemente por acudir al contenido del mencionado artículo 1 en apoyo de la tesis de la desconexión de las confesiones religiosas del régimen de la garantía común del derecho de asociación (8). Los planteamientos que adoptan este particular enfoque de la cuestión, en el mejor de los casos, denotan una percepción incompleta y asis-

(7) Así, por ejemplo, S. PÉREZ EsCALONA, El Derecho de Asociación y las Asociaciones en el Sistema Constitucional Español, Cizur Menor, 2007, págs. 78 y sigs.

(8) En este sentido, entre otros, D. LlAMAZARES, «Libertad de conciencia y laicidad en la Constitución Española de 1978», en J. FERREIRO (coord.), Jornadas Jurídicas sobre Libertad Religiosa en España, Madrid, 2008, págs. 120-21; J. MANTECóN, «Praxis administrativa y jurisprudencia en torno a la inscripción de las confesiones y entidades confesionales en el Registro de Entidades Religiosas», en J. J. GONZÁlez RIVAS (dir.), Pluralismo religioso y Estado de Derecho, Madrid, 2004, págs. 316-17; A. C. Álvarez CortinA, «La autonomía de las confesiones religiosas», en A. C. ÁlVAREz CORTINA y M. RODRÍGUEZ BlANCO (coords.), La libertad religiosa en España. XXV años de vigencia de la Ley Orgánica 7/1980, de 5 de julio (Comentarios a su articu- 
temática del sector del ordenamiento jurídico sobre el que opera la elaboración dogmática $\mathrm{y}$, con frecuencia, revelan una errónea concepción del significado y alcance de la garantía común asociativa en la Constitución y de su relación con los regímenes asociativos especiales.

En todo caso, como después haré notar, la defectuosa redacción de la cláusula que delimita el ámbito de aplicación de la LODA se ha visto incidentalmente avalada en su vigencia por el Tribunal Constitucional, en su sentencia de 27 de abril de 2006 sobre la ley catalana de asociaciones, aunque, por otra parte, como era de suponer, al no haber reparado aquí el Tribunal en el carácter tan ostensiblemente antinómico de dicha cláusula, los razonamientos que se avanzan en la sentencia no logran sortear las inevitables contradicciones normativas a que da lugar la exclusión del ámbito de aplicación de la LODA de las asociaciones sujetas a un régimen especial respecto del significado de la garantía común asociativa que el Tribunal dice al mismo tiempo asumir. Y así, frente al papel depurador del ordenamiento que corresponde al Tribunal Constitucional, tanto la perspectiva de enjuiciamiento adoptada como el propio desarrollo argumental en esa sentencia acaban convirtiéndose, por el contrario, en mera correa de transmisión de las contradicciones y antinomias en las que previamente incurrió el legislador del derecho de asociación.

\section{EL ESTATUTO DE LAS CONFESIONES ANTE LA EXIGENCIA DE DEMOCRACIA INTERNA ASOCIATIVA EN LA LODA}

El artículo 2.5 de la LODA, en su primer inciso, proclama textualmente que la organización interna y el funcionamiento de las asociaciones deberán ser democráticos. Esta previsión, al decir de algunos autores, vendría a confirmar la idea, muy extendida nuevamente entre la doctrina eclesiasticista, en cuya virtud el reconocimiento de la plena autonomía de las confesiones en la ley de libertad religiosa y la consiguiente posibilidad de establecer cláusulas de salvaguarda de la identidad religiosa y del carácter propio (cfr. art. 6 LOLR) constituyen, en nuestro ordenamiento, una excepción respecto del régimen común de derechos y libertades y, particularmente, respecto de la legislación general en materia asociativa; desde esa óptica, por lo demás, ese carácter excepcional y privilegiado justificaría, a modo de contrapartida, la realización de un control material en

lado), Granada, 2006, pág. 190; J. M. PORRAS RAMíREZ, Libertad religiosa, laicidad y cooperación con las confesiones en el Estado democrático de Derecho, Cizur Menor, 2006, pág. 64. 
el trámite de acceso al Registro de Entidades Religiosas como el que, de hecho, ha llevado a cabo la Administración en las últimas décadas.

En mi criterio, sin embargo, nada hay de excepcional en el reconocimiento de la plena autonomía confesional en la ley de libertad religiosa, pues una tal plena autonomía, tanto organizativa y funcional como asimismo ideológica, forma ya parte integrante del contenido esencial del derecho fundamental a la libertad de asociación y en este sentido se ha pronunciado claramente la jurisprudencia constitucional. Sólo cabe excepcionalmente entender aplicable semejante mandato de democracia interna en el supuesto de aquellas asociaciones de relevancia constitucional en cuyo estatuto iusfundamental propio así se dispone [y aun en ese caso dicho mandato no afecta a la plena libertad de conformación ideológica de la entidad sino sólo a su estructura y funcionamiento (9)], quedando intacta para las restantes modalidades asociativas la garantía de la plena autonomía para establecer sus privativas reglas de organización y funcionamiento y sus propios fines asociativos, no necesariamente democráticos en ambos casos, con el único límite de la tipificación penal en cuanto a las finalidades perseguidas o a los medios utilizados por la asociación (10).

Así pues, ante todo, la singular exigencia general de democracia interna en la LODA plantea, en primer lugar, un problema de adecuación al contenido de la garantía común asociativa a cuyo desarrollo directo viene a servir esta ley y, de hecho, la mayor parte de la doctrina científica desde muy temprano planteó sus serias dudas acerca de la constitucionalidad del precepto legal en cuestión, precisamente por considerarlo contrario al contenido esencial de la libertad de asociación (11).

(9) En este sentido, entre otros, M. ARAGÓN, Constitución y democracia, Madrid, 1989, pág. 112; J. JIMÉNEZ CAMPO, «Sobre el régimen jurídico-constitucional de los partidos políticos», en Revista de Derecho Político, núm. 26, 1988, pág. 24.

(10) Más ampliamente, J. R. Polo, La naturaleza jurídica de las confesiones religiosas..., op. cit., págs. 143 y sigs.

(11) Así, por ejemplo, entre otros muchos, CAPILla RONCERO, F., «Las asociaciones», en F. Blasco (coord.), Derecho Civil. Parte general. Derecho de la persona, Valencia, 2003, pág. 412; L. DíEz-PiCAzo y A. Gullón, Sistema de Derecho Civil, I, Madrid, 2005, pág. 604; J. M. BILBAO, «Prohibición de discriminación y relaciones entre particulares», en Teoría y Realidad Constitucional, núm. 18, 2006, pág. 178; A. ELVIRA, «Asociaciones y democracia interna», en AAVV, La democracia constitucional. Estudios en homenaje al Profesor Francisco Rubio Llorente, Madrid, 2002, pág. 630; J. PÉREZ RoYO, Curso de Derecho Constitucional, Madrid, 2005, pág. 447; J. GONZÁlez PÉREZ y G. FERnÁndeZ FARRERES, Derecho de Asociación..., op. cit., pág. 131; I. BELUCHE, «La autonomía estatutaria y el principio democrático en la organización de las asociaciones», en J. M. ABRIL y M. E. AMAT (coords.), Homenaje al Profesor Lluis Puig i Ferriol, I, Valencia, 2006, págs. 342 y sigs. En contra de esta idea vid., entre otros, A. QUESADA, «Democracia interna 
No obstante, este particular abordaje metodológico del problema jurídico aquí planteado, que resulta obligado en buena técnica de interpretación constitucional, ha estado, por lo común, injustificadamente ausente de las argumentaciones propuestas por aquellos autores que sostienen el carácter excepcional de la plena autonomía confesional en la LOLR y que, las más de las veces, se han limitado a señalar que el artículo 2.5 de la LODA viene a confirmar la premisa de esa referida excepcionalidad, sin plantearse siquiera el tema de la validez o no de ese precepto legal y de su posible falta de adecuación a los postulados del artículo 22 de la Constitución. Bien es cierto que, aun de manera muy minoritaria, desde algunas otras posiciones doctrinales se ha prestado una mayor atención al contexto sistemático en el que se inserta la ley del derecho de asociación y, como consecuencia de ello, en la elaboración dogmática se ha tenido al menos en cuenta el problema que plantea el artículo 2.5 de la LODA en su relación con la garantía constitucional asociativa, sin perjuicio de que, aun así, se haya terminado por concluir en estos casos que esa presunta inconstitucionalidad del precepto no está demostrada ni declarada por parte del Tribunal Constitucional y ello se haya estimado suficiente para proclamar el carácter excepcional de la autonomía confesional en la ley de libertad religiosa (12); en este otro tipo de planteamientos, la perspectiva de análisis, cuando menos, se muestra más atenta a las exigencias hermenéuticas propias de nuestro sistema constitucional, si bien, como seguidamente trataré de demostrar, la conclusión alcanzada tampoco se ha visto confirmada por la doctrina del Tribunal Constitucional recaída en torno al precepto que nos ocupa y que, en lo sustancial, ha venido a dar la razón a quienes postulamos que nada hay de excepcional en el reconocimiento de la plena autonomía confesional que se aprecia en el régimen especial de las entidades religiosas.

El Tribunal Constitucional, en efecto, se pronunció sobre el significado del artículo 2.5 de la LODA en su sentencia de 27 de abril de 2006, y lo hizo en los siguientes términos: «se aprecia que mientras el artículo $22 \mathrm{CE}$, regulador del derecho fundamental de asociación, nada dice sobre la exigencia de que tal derecho se deba materializar en asociaciones organizadas de modo democrático y funcionando en igual sentido (precisamente la STC 173/1998, FJ 8, reiterará que forma parte del derecho de asociación garantizado en el art. 22 CE la libertad de autoorganización), otros preceptos constitucionales

y asociaciones: reflexiones desde una óptica civil», en Diario La Ley, núm. 7062 (24 de noviembre de 2008), y la bibliografía allí citada.

(12) En este sentido, por ejemplo, M. J. RocA, Derechos fundamentales y autonomía de las iglesias, Madrid, 2005, pág. 104. 
reguladores de tipos singulares de asociación, como son los partidos políticos, las asociaciones empresariales o los sindicatos de trabajadores, disponen, ciertamente, que dicha estructura interna y funcionamiento sean de carácter democrático [...] Como consecuencia, del diferente trato que la Constitución otorga en este punto a determinadas formas de asociación respecto de las asociaciones en general surgidas del ejercicio del derecho, cabría cuestionarse la constitucionalidad de la hipotética imposición por el legislador de la exigencia de estructura y funcionamiento democráticos a todas las asociaciones que configure, tengan o no relevancia pública, con la correspondiente limitación de su libertad de autoorganización. En respuesta a este planteamiento, hay que decir que no es esa imposición general la que parece desprenderse del artículo 2.5 LODA, y ello, de un lado, porque el mismo, como es obvio, ha de interpretarse constitucionalmente, $\mathrm{y}$, de otro, porque dicho artículo no extiende la aludida exigencia a cualquier tipo de asociaciones, pues el artículo 1.3 y 4 de la propia LODA excluye de su ámbito de aplicación a numerosas figuras asociativas» (STC 135/2006, FJ 5).

El Alto Tribunal aquí, como se ve, reiterando el sentido de su doctrina precedente acerca del derecho a la libertad de asociación, confirma la idea de que la plena autonomía organizativa, funcional e ideológica forma ya parte integrante del contenido esencial de ese derecho fundamental y, como consecuencia de ello, sugiere que «cabría cuestionarse» la constitucionalidad de la extensión del mandato de democracia interna a todas las asociaciones, más allá de aquellas asociaciones de relevancia constitucional sobre las que ya pesa ese mandato específico en su particular régimen constitucional. A este respecto, a menos que se trate de una suerte de pregunta retórica, no se termina de entender la razón por la que el Tribunal se pronuncia en estos términos, acaso un tanto dubitativos, ya que, aceptada la premisa de que la plena autonomía organizativa y funcional forma parte del contenido de la garantía común asociativa, no parece que quepa entonces otra opción que la de proclamar directamente y sin ambages que una tal extensión del mandato de democracia interna sería en efecto inconstitucional y decretar así la invalidez del artículo 2.5 de la LODA, aunque seguramente haya influido aquí el hecho de que la sentencia esté juzgando la constitucionalidad de ciertos preceptos de una ley autonómica asociativa y sólo incidentalmente se esté pronunciando acerca del sentido que deba otorgarse al precepto de la ley estatal, con lo que de invalidar en esta sede la mencionada disposición de la LODA la sentencia estaría seguramente incurriendo en incongruencia extra petitum, y ésta parece ser la razón por la que algún autor sostiene que, en sentido estricto, sólo el planteamiento de una cuestión de inconstitucionalidad relativa al precepto en cuestión $-\mathrm{o}$ de un 
recurso de inconstitucionalidad, habría tal vez que añadir - podría despejar definitivamente este dilema (13).

Llegados a este punto, el Tribunal, haciendo uso en apariencia de la técnica empleada en las conocidas como sentencias interpretativas, opta por esclarecer el sentido en el que debe ser interpretado el artículo 2.5 de la LODA para no contravenir el contenido esencial de la libertad de asociación, esto es, para ser interpretado constitucionalmente, y en efecto nos dice que esa interpretación constitucionalmente adecuada pasa por entender que de este precepto legal no puede hacerse derivar la imposición general a todas las asociaciones de la exigencia de democracia interna. Lo extraño es que la sentencia afirme que no es ésa la imposición general que parece desprenderse del artículo 2.5 de la LODA, porque, muy al contrario, lo cierto es que ésa es exactamente la imposición general que se desprende de lo dispuesto en esa norma, y de hecho así lo han entendido todos aquellos autores que, como quedó apuntado, han cuestionado abiertamente la constitucionalidad del precepto. Y más extraño aún, si cabe, resulta el hecho de que el Tribunal recurra a la más que dudosa delimitación del ámbito de aplicación de la ley para apoyar la idea de que, realmente, el artículo 2.5 no impone generalizadamente la exigencia de democracia interna puesto que no es aplicable, según lo establecido en el artículo 1 de la LODA, a todas aquellas asociaciones dotadas de una legislación especial; al hacer uso la sentencia de esta cláusula delimitadora con ese propósito y, en cierto modo, avalar con ello su validez y corrección técnica, el Tribunal Constitucional parece estar pasando por alto las consecuencias que se derivan de su carácter tan ostensiblemente antinómico, en los términos que expuse, porque lo cierto es que, pese a lo que indica aquí la sentencia, el artículo 2.5 tiene rango de ley orgánica (cfr. Disposición Final Primera) y, consecuentemente, a tenor de lo establecido en la cláusula de supletoriedad, ese precepto sí resulta sin duda aplicable a todos los regímenes asociativos especiales.

Se diría que la deficiente comprensión, por parte del legislador del derecho de asociación, de los presupuestos constitucionales en los que se basa su regulación no sólo ha desconcertado a buena parte de la doctrina científica sino que, también, ha afectado a la doctrina del Tribunal Constitucional, incapaz en apariencia de sustraerse a las serias contradicciones a las que inevitablemente aboca el antinómico enunciado del artículo 1 de la LODA.

(13) Cfr. D. GIMÉNEZ GLUCK, «Asociación, discriminación y Constitución: los límites entre la autonomía asociativa y el derecho de los socios — y aspirantes a serlo - a no ser discriminados», en Revista de Derecho Político, núm. 79, 2010, pág. 149. 
Con todo, lo que parece indudable es que el Tribunal Constitucional, en este pronunciamiento, ha venido a dar la razón, en última instancia, a quienes venimos desde hace tiempo sosteniendo que el reconocimiento de la plena autonomía de las confesiones religiosas en su legislación especial no constituye, en absoluto, una excepción respecto del contenido de la garantía común asociativa en la Constitución, y de ello da fe la confirmación de la premisa de que «el constituyente quiso que determinadas asociaciones, por la relevancia de las funciones que se les reconocía, hubieran de tener de modo necesario una organización y funcionamiento democráticos, pero no impuso ese principio a cualquier otra asociación surgida del ejercicio del derecho fundamental de asociación» (STC 135/2006, FJ 5), tanto como la proclamación en esta sentencia de que el artículo 2.5 de la LODA debe ser interpretado constitucionalmente, pese a su tenor literal, en el sentido de que no necesariamente la organización y el funcionamiento de todas las asociaciones deberán ser democráticos. Cuestión distinta es la forma y los cauces por los que el Tribunal ha llegado a estas conclusiones y que, a su vez, generan razonablemente otras tantas incógnitas, como la que cabe plantear acerca de si con su resolución el Tribunal no habrá ya declarado implícitamente inconstitucional el artículo 2.5 de la LODA, tal y como se ha sugerido (14), o, desde otra perspectiva, como la que concierne a la sospecha de que el Tribunal, tal vez a causa de su dudoso recurso a la implicación en este asunto de la no menos dudosa cláusula del artículo 1 de la ley, pudiera haber traspasado aquí los límites aceptables de la técnica de las sentencias interpretativas, suplantando de hecho el papel que corresponde al legislador, al conferir al precepto enjuiciado un sentido tan ostensiblemente opuesto al que aparentemente se desprende de su enunciado normativo; pero éstos son, al cabo, interrogantes cuya respuesta más fundamentada excede con creces el propósito de estas páginas y quedan, por tanto, ahora sólo apuntados.

\section{LA MENCIÓN IMPLÍCITA DE LAS ASOCIACIONES CATÓLICAS EN LA LODA Y EL PESO DE LA TRADICIÓN CONCORDATARIA}

En el marco de la delimitación del ámbito de aplicación de la ley, el artículo 1.3 de la LODA, en su segundo inciso, dispone que «las asociaciones constituidas para fines exclusivamente religiosos por las iglesias, confesiones

(14) Cfr. A. ElvirA, «A vueltas con el derecho de asociación (Comentario a las Sentencias 133 y 135/2006, ambas de 27 de abril)», en Revista Española de Derecho Constitucional, núm. 83, 2008, págs. 318-319. 
y comunidades religiosas se regirán por lo dispuesto en los tratados internacionales y en las leyes específicas, sin perjuicio de la aplicación supletoria de las disposiciones de la presente Ley Orgánica».

Si se va más allá del enunciado formalmente genérico de esta norma y se atiende al contenido de los trabajos parlamentarios que tuvieron lugar en el proceso de tramitación de la ley, se comprobará, entonces, que la finalidad de esta peculiar disposición no fue allí otra que la de dotar de una cobertura formal, en el nuevo ordenamiento asociativo, a las asociaciones propias de la Iglesia católica que ya gozaban de su particular régimen de reconocimiento de la personalidad civil instaurado en el correspondiente acuerdo concordatario suscrito entre el Estado español y la Santa Sede, con rango, ya se sabe, precisamente de tratado internacional. Es más, el enunciado final de esta norma no es, ni mucho menos, el que inicialmente se propuso en el trámite parlamentario, a cuyo tenor habrían de regirse por su legislación específica «las asociaciones de la Iglesia Católica que hayan adquirido personalidad jurídica civil de conformidad con lo dispuesto en la ley». Sin embargo, esta propuesta no prosperó, al estimarse entonces que era necesario diferenciar entre las asociaciones creadas por la Iglesia para fines exclusivamente religiosos y las creadas para otros fines distintos, $y$, seguidamente, dejar sometidas estas últimas a la legislación general asociativa y evitar con ello un posible conflicto de igualdad respecto de las asociaciones creadas para fines no exclusivamente religiosos por parte de otras confesiones distintas de la católica (15).

Esta norma, por lo demás expresiva de una peculiar dinámica de reconocimiento particular de las entidades católicas visiblemente lastrada por el peso de la herencia concordataria, como igualmente acontece en tantos otros sectores del Derecho Eclesiástico del Estado, suscita, de entrada, algunas cuestiones relevantes que conviene ahora sólo dejar esbozadas: cabe, por ejemplo, preguntarse acerca de la razón por la que la consagración, en el texto final de la norma, de un distinto tratamiento jurídico para las asociaciones con fines exclusivamente religiosos, dependiendo de su adscripción a una u otra confesión (régimen especial concordatario para las de filiación católica y ley de libertad religiosa para las demás), no suscitó en el prelegislador del derecho de asociación la misma o similar sospecha de discriminación que la que había suscitado la fórmula legal inicialmente propuesta respecto de las asociaciones con fines no exclusivamente religiosos; cabe, también, preguntarse acerca del motivo por el que, en la LODA, únicamente se contempla esa remisión a lo previsto en los tratados in-

(15) Vid. sobre todo ello J. GonZÁlez Pérez y G. Fernández FArReres, Derecho de Asociación..., op. cit., págs. 51-52. 
ternacionales a propósito de estas asociaciones creadas por la Iglesia católica, y no se hace lo mismo, con un carácter más general, ya en la propia delimitación del ámbito de aplicación de la ley en el primer inciso del artículo 1.3 (algo así como «se regirán por su legislación específica o por lo dispuesto en los tratados internacionales...»), dado que, como se sabe, es realmente el estatuto jurídico de la Iglesia católica y de sus entidades, en su totalidad, el que quedó de hecho situado extramuros de la Ley Orgánica de Libertad Religiosa al encontrarse ya, a la promulgación de esta ley, establecido íntegramente en los acuerdos concordatarios de 1979 (16).

En cualquier caso, teniendo en cuenta que la LODA se presenta a sí misma como la ley que desarrolla orgánicamente el régimen constitucional del derecho de asociación, esa remisión a lo dispuesto en los tratados internacionales permite hacer dudar, en mi opinión fundadamente, de que ese desarrollo se esté produciendo aquí conforme a las pautas constitucionalmente exigidas, pues no parece un tratado internacional el instrumento normativo adecuado para llevar a cabo un desarrollo directo del derecho fundamental que en nuestro ordenamiento le está reservado, por el contrario, a la ley orgánica, y con sujeción, además, a los principios de generalidad y objetividad; y es que, en efecto, en el Acuerdo sobre Asuntos Jurídicos de 3 de enero 1979 no sólo se procede a adaptar el régimen de ejercicio del derecho de asociación a las peculiaridades propias de las entidades católicas en determinados aspectos puntuales y adyacentes al núcleo del derecho fundamental sino que, antes bien, se instaura todo un régimen particular de reconocimiento de dichas entidades, en el que se ven afectados y dotados de un estatuto propio y diferenciado determinados aspectos que conciernen claramente a las condiciones básicas de ejercicio de la libertad asociativa.

Hoy sabemos, con fundamento en la doctrina del Tribunal Constitucional, que la posibilidad de hacer depender la adquisición de la personalidad jurídica de la efectiva satisfacción del trámite de la inscripción registral se encuentra fuera del contenido esencial del derecho de asociación y constituye, más bien, no siendo una cuestión que afecte a la constitucionalidad de la norma, una mera opción que puede libremente adoptar o no el legislador (cfr. STC 48/2003, FJ 20). Sin embargo, en mi criterio, no puede decirse lo mismo, por ejemplo, del régimen de acceso a dicha personalidad civil que el acuerdo concordatario instaura para ciertas entidades católicas sin necesidad de satisfacer la carga de la inscripción en el Registro de Entidades Religiosas que la LOLR prevé, como requisito general y común, para todas las entidades que aspiran

(16) Vid., más ampliamente, J. R. Polo, La naturaleza jurídica de las confesiones religiosas..., op. cit., págs. 222-228. 
a ver reconocida su personalidad jurídica religiosa ante el Estado; porque, en efecto, en este caso sí puede decirse que se ve concernido el núcleo esencial del derecho fundamental, respecto de cuyo ejercicio la Constitución impone la carga de la inscripción registral, que es, cabalmente, una condición de plenitud en el ejercicio de esta libertad, pues, al decir de la jurisprudencia constitucional, «es claro que la libertad de asociación no se realiza plenamente sino cuando se satisface la carga de la inscripción registral que la Constitución impone (art. 22.3) y que la Administración no puede denegar arbitraria o inmotivadamente» (STC 291/1993, FJ 2).

Hemos de entender, por tanto, que la ley de libertad religiosa impone dicha carga como condición de plenitud en el ejercicio del derecho de asociación en materia religiosa, de manera que el establecimiento, por la vía pacticia, de un régimen particular de reconocimiento que exceptúa ese trámite de la inscripción respecto de algunas entidades católicas representa una modificación de las condiciones básicas de ejercicio del derecho fundamental, para la que la norma concordataria no está en absoluto habilitada en nuestro sistema constitucional. Y ello por no mencionar las evidentes implicaciones que aquí también presenta el principio constitucional de igualdad, que no me parecen menos relevantes. En la valoración conjunta de ambos aspectos, en todo caso, no puede ignorarse que los acuerdos concordatarios, en tanto que tratados internacionales, ostentan en nuestro Derecho un rango netamente infraconstitucional, y están, por tanto, plenamente subordinados a los principios que conforman el sistema de derechos y libertades en la ley fundamental, plenamente sujetos en su interpretación y aplicación, en suma, a los condicionantes que derivan del reconocimiento, en plano de igualdad, de la garantía común asociativa en la Constitución.

Frente a lo que en ocasiones se afirma por parte de un cierto sector de la doctrina eclesiasticista, no es la Constitución (y su desarrollo orgánico en la ley de libertad religiosa o en la ley del derecho de asociación) la que debe interpretarse, en ésta ni en ninguna otra materia, conforme a lo establecido en los acuerdos concordatarios, sino exactamente a la inversa, y desde luego no parece que pueda sostenerse con un mínimo de seriedad, como ha hecho incluso algún autor (17), que los acuerdos concordatarios deben ser encuadrados en la categoría de los tratados internacionales en materia de derechos fundamentales a los que hace mención el canon hermenéutico del artículo 10.2 de la Constitución, una tesis ciertamente pintoresca que, a mi modo de ver, carece del menor fun-

(17) Cfr. J. MARTínEZ TORRÓN, «Jerarquía y antinomias de las fuentes del nuevo Derecho Eclesiástico español», en Anuario de Derecho Eclesiástico del Estado, III, 1987, pág. 134. 
damento en nuestro sistema de fuentes aun teniendo en cuenta el criterio amplio que la doctrina del Tribunal Constitucional ha utilizado en este tema (18).

\section{RESUMEN}

En este trabajo se examina críticamente el significado de los preceptos de la Ley Orgánica del Derecho de Asociación que más directamente conciernen al estatuto de las confesiones religiosas, concebidas en la Exposición de Motivos de esta ley como auténticas asociaciones de relevancia constitucional. Partiendo de esta premisa, se analizan las que el autor considera claras antinomias y contradicciones internas entre algunos de los preceptos de la ley, así como entre algunas de sus disposiciones y la doctrina previamente sentada por el Tribunal Constitucional en torno a la llamada garantía común asociativa en la norma fundamental, aspectos éstos que, en última instancia, aparentemente contradicen el referido entendimiento en la ley de las confesiones como tales asociaciones de relevancia constitucional $\mathrm{y}$, asimismo, denotan una deficiente comprensión por parte del legislador de los presupuestos en los que se basa el desarrollo directo del derecho fundamental a la libertad de asociación.

PALABRAS CLAVE: confesiones religiosas; derecho de asociación; asociaciones de relevancia constitucional.

\section{ABSTRACT}

This paper deals with the proper meaning that should be given to the provisions concerning the legal status of religious denominations in the current spanish freedom of association act. In this particular statute, religious denominations are considered to be one of the specific types of associations expressly mentioned and protected by the Constitution. Assuming the propriety of this particular conception, the author here examines the presence and scope of certain legal contradictions that can be perceived in this legal context, and also tries to highlight the main consequences that, in his view, arise from the presence of those clear legal antinomys.

KEY WORDS: religious denominations; freedom of association; expressive associations.

(18) Vid., al respecto, J. R. POLo, La naturaleza jurídica de las confesiones religiosas..., op. cit., págs. 254-57. 